\title{
DEVELOPMENTAL CHANGES IN FRONTOCORTICAL MORPHOLOGY AND NEUROCHEMISTRY OF NEONATAL RATS FOLLOWING GESTATIONAL NICOTINE EXPOSURE
}

\author{
Omotoso Gabriel Olaiya, Alabi Adeolu Stephen, Akinola Oluwole Busayo, Enaibe Bernard Ufuoma
}

Omotoso G.O. Department of Anatomy, Faculty of Basic Medical Sciences, College of Health

Sciences, University of Ilorin, P.M.B. 1515, Ilorin. Email: gabrielolaiya@yahoo.com Tel No:

+2347030505707

\begin{abstract}
Exposure of the embryo or foetus to nicotine during development results in some forms of neurological deficits later in life. The current study aimed at determining the effects of prenatal nicotine administration during the $1^{\text {st }}$ and $2^{\text {nd }}$ gestational weeks on the frontal cortex of neonatal Wistar rats. For each week of gestation, pregnant Wistar rats were assigned to 3 groups: a control group (1), and two treated groups (2 and 3), and were given intra-peritoneal nicotine at $6.88 \mathrm{mg} /$ $\mathrm{kg}$ and $13.76 \mathrm{mg} / \mathrm{kg}$ doses respectively. The weights of the litters were taken at birth and at postnatal day 4; the whole brain and frontal cortical weights were also assessed. Tissues for histological demonstration were fixed in freshly prepared formol calcium, while specimen for biochemical studies were homogenised and processed for the determination of alkaline phosphatase (ALP) and malondialdehyde (MDA) activities. Findings in the treated animals showed low birth weights, raised ALP but reduced MDA, with corresponding alterations in the cortical cytoarchitecture, which could explain some of the pathological basis for the neurobehavioural problems associated with offspring of women smokers.

Keywords: Prenatal nicotine, Frontal cortex, Morphology, Histology, ALP, MDA
\end{abstract}

\section{INTRODUCTION}

Gestational exposure to nicotine is one of the most modifiable causes of morbidity and mortality for both the mother and foetus (Blood-Siegfried and Rende, 2010). Nicotine, a principal component of tobacco, is one of the most heavily abused drugs in the world, exerting deleterious effects on the health of the foetus, newborn, child, and adolescent exposed to it (Rogers, 2008; Omotoso et al., 2013). Maternal tobacco smoking or nicotine administration impairs placental development, with a resultant decline in the transfer of oxygen and essential nutrients from the mother to the foetus and can result in premature delivery, foetal growth restriction, and other developmental abnormalities in the newborn (Castles et al., 1999). Several other components of tobacco are all linked to one or more clinical conditions of the brain, cardiovascular and respiratory systems, among other systems and organs of the body
(Omotoso and Adeyemi, 2014; Kohlmeier, 2015). Nicotine is a neuroteratogen that alters replication and differentiation of neural cells, leading to abnormalities of synaptic biochemistry and behavioural deficits (Roy et al., 2002). Nicotinic receptor up-regulation is indicative of chronic cell stimulation by nicotine, and is a hallmark of nicotine-induced neuroteratogenesis (Slotkin et al., 2002).

Nicotine is capable of modulating enzyme activities (Yildiz et al., 1998). Vascular injury resulting from ischemic process leads to reduction in the supply of oxygen and nutrients to the brain, thereby causing various forms of degenerative changes in the brain tissue (Yildiz et al., 1998). Some embryonic movements important during embryogenesis for the differentiation and maturation of the embryo's organ systems could be altered by exposure to nicotine (Ejaz et al., 2005). 
Prenatal exposure to nicotine is increasingly being demonstrated to be one of the main contributors to developmental neurological alterations and neurobehavioural problems in the offspring of users (Lavezzi et al., 2007). Nicotine crosses the placenta and concentrates in the foetus at levels slightly higher than those in the mother. It is associated with the development of learning disabilities, attention deficit disorders, hyperactivity and other behavioural disorders in children of smokers, and this relationship is dose-dependent (Linnet et al., 2003; Durazzo et al., 2007). At low doses, it induces hyperactivity, but hypo-activity at higher doses (Ejaz et al., 2005). Infants of smokers show evidence of problems with discrimination of consonant and vowel syllables (Key et al., 2007), when compared with infants of non-smokers, who also exhibit

\section{METHODOLOGY}

\section{Experimental Animals}

Virgin Male and Female Wistar rats of the same filial generation were bred and used for the study. The rats aged between 11-12 weeks with mean weight $194.70 \pm 3.01 \mathrm{~g}$. They were kept in different cages at normal temperature, and maintained under a $12 \mathrm{~h}$ light/ $12 \mathrm{~h}$ dark cycle, with feeds (rat pellets) and water available ad libitum.

\section{Experimental Design}

Vaginal smears of the female rats were carried out to determine their oestrous cycle before exposure to the male rats for mating, and pregnancy was confirmed (Marcondes et al., 2002). The day of confirmation of pregnancy was taken to be Day 0 . Eighteen (18) pregnant rats were randomly grouped into two (2): Groups A ( $1^{\text {st }}$ gestational week) and $B$ ( $2^{\text {nd }}$ gestational week), with each group subdivided into 3 (1-3), as shown below. Treatment was via intra-peritoneal administration for 5 consecutive days during the respective gestational periods of each group (Ferrari et al., 2002)

Group $A_{1}$ : received $0.1 \mathrm{ml}$ of normal saline on days 2-6 of the $1^{\text {st }}$ gestational week

Group $A_{2}$ : received low dose nicotine (6.88 $\mathrm{mg} / \mathrm{kg}$ ) on days 2-6 of the $1^{\text {st }}$ gestational week more common forms of brain lateralization for speech.

Alkaline phosphatase (ALP), a membrane marker, facilitates transport across cell membranes; it causes breakdown of ATP to ADP and inorganic phosphate, thereby making free energy available for metabolic processes (Murray et al., 2003). Any alteration in the level of this enzyme is indicative of a compromise in cell membrane composition and functions. In determining lipid peroxidation, a principal component of thiobarbituric acid reactive substances, malondialdehyde (MDA), can be assessed (Oyewopo et al., 2010). The aim of this study was to determine how nicotine administration during the $1^{\text {st }}$ and $2^{\text {nd }}$ week of gestation affects the frontal cortex of young Wistar rats.
Group $A_{3}$ : received high dose nicotine (13.76 $\mathrm{mg} / \mathrm{kg}$ ) on days $2-6$ of the $1^{\text {st }}$ gestational week

Group $B_{1}$ : received $0.1 \mathrm{ml}$ of normal saline on days $9-13$ of the $2^{\text {nd }}$ gestational week

Group $B_{2}$ : received low dose nicotine (6.88 $\mathrm{mg} / \mathrm{kg}$ ) on days $9-13$ of the $2^{\text {nd }}$ gestational week

Group $B_{3}$ : received high dose nicotine (13.76 $\mathrm{mg} / \mathrm{kg}$ ) on days $9-13$ of the $2^{\text {nd }}$ gestational week.

The pregnant rats were monitored daily and their weights taken. After delivery, the weights of the litters were also taken at birth and before sacrifice. They were observed daily for any developmental and behavioural changes.

\section{Animal Sacrifice, Tissue Collection and Processing}

The litters were sacrificed by cervical dislocation on postnatal day 4 . The skull was dissected and the brain exposed. It was weighed, and the excised frontal cortex was weighed too. The tissue specimen for histological examination was fixed in freshly prepared formol calcium and tissue processing done using the Haematoxylin and Eosin staining techniques. 


\section{Biochemical Studies}

Tissue specimens for biochemical studies were weighed, placed in chilled $0.25 \mathrm{M}$ sucrose solution, and homogenized using a homogenizer. The homogenate was centrifuged at $5000 \mathrm{rpm}$ for $5 \mathrm{~min}$ using a centrifuge (Gallenkomp, England). The supernatant was collected using Pasteur pipettes, and stored in the freezer for onward enzyme analysis. The tissue activities of alkaline phosphatase enzyme and malondialdehyde (MDA) were determined through spectrophotometry (Colorimetric method), using appropriate biochemical kits from RANDOX® (Antrim, UK), and Quimica Clinica Aplicada $₫($ Spain).

\section{Statistical Analysis of Data}

Data obtained from the biochemical investigation was analysed statistically using student's t-test, and presented as Mean \pm SEM, with determination of level of significance, at $p$ values $<0.05$.

\section{RESULTS}

\section{Physical Observation}

No obvious changes were noticed in the physical appearance, activity, and feeding habits of the litters from birth till the postnatal day 4 (PND 4) of sacrifice. No apparent changes or abnormalities were observed in the brain specimen too. However, the birth weights of the pups treated with prenatal nicotine in both $1^{\text {st }}$ and $2^{\text {nd }}$ gestational weeks reduced compared with their respective controls (Table 1 ). The reduction was significantly more in animals that received the high dose of prenatal nicotine $(p<0.05)$, compared to those that received the low dose. There was also a significant difference in the birth weight reduction seen between the high dose groups of the $1^{\text {st }}$ and $2^{\text {nd }}$ gestational week groups ( $p<0.05)$, but no statistically significant difference in the weights of animals at PND 4, between the groups of each week ( $p>0.05)$.

Brain weights of treated animals in the $1^{\text {st }}$ week increased compared to the control, and this was statistically significant in the group that received the high dose of prenatal nicotine $(p<0.05)$ (Figure 1$)$. In the $2^{\text {nd }}$ week however, there was reduction in brain weights, with the low dose group having the lower weight record compared to the high dose group ( $p>0.05)$.

Table 1: Weights of animals in the first four days of life

A: $1^{\text {st }}$ Gestational Week

B: $2^{\text {nd }}$ Gestational Week

\begin{tabular}{|c|c|c|c|c|c|c|}
\hline & $A_{1}$ : Control & $\begin{array}{l}\mathrm{A}_{2}: 6.88 \\
\mathrm{mg} / \mathrm{kg} \\
\text { nicotine }\end{array}$ & $\begin{array}{l}\mathrm{A}_{3}: 13.76 \\
\mathrm{mg} / \mathrm{kg} \\
\text { nicotine }\end{array}$ & $\begin{array}{l}\text { B }_{1}: \\
\text { Control }\end{array}$ & $\begin{array}{l}\mathrm{B}_{2}: 6.88 \\
\mathrm{mg} / \mathrm{kg} \\
\text { nicotine }\end{array}$ & $\begin{array}{l}\mathrm{B}_{3}: 13.76 \mathrm{mg} / \\
\mathrm{kg} \text { nicotine }\end{array}$ \\
\hline Birth weight (g) & $7.0 \pm 0.3 * \S$ & $5.5 \pm 0.2^{*}$ & $5.1 \pm 0.2^{\S \gamma}$ & $5.9 \pm 0.2^{\phi}$ & $5.8 \pm 0.1^{\ddagger}$ & $4.4 \pm 0.1^{\phi \neq}$ \\
\hline $\begin{array}{l}\text { Weight at PND } \\
4(\mathrm{~g})\end{array}$ & $6.5 \pm 0.1$ & $5.2 \pm 0.03$ & $7.3 \pm 0.1$ & $9.4 \pm 0.8$ & $7.1 \pm 0.2$ & $8.4 \pm 0.04$ \\
\hline $\begin{array}{l}\text { Weight } \\
\text { Difference (g) }\end{array}$ & -0.5 & -0.3 & 2.2 & 3.5 & 1.3 & 4.0 \\
\hline
\end{tabular}

Birth weight was statistically significant $(p<0.05)$ between: ${ }^{*} A_{1}$ and $A_{2} ;{ }^{\S} A_{1}$ and $A_{3} ;{ }^{\phi} B_{1}$ and $B_{3} ;{ }^{\ddagger} B_{2}$ and $B_{3}$; and ${ }^{Y} A_{3}$ and $B_{3}$. 


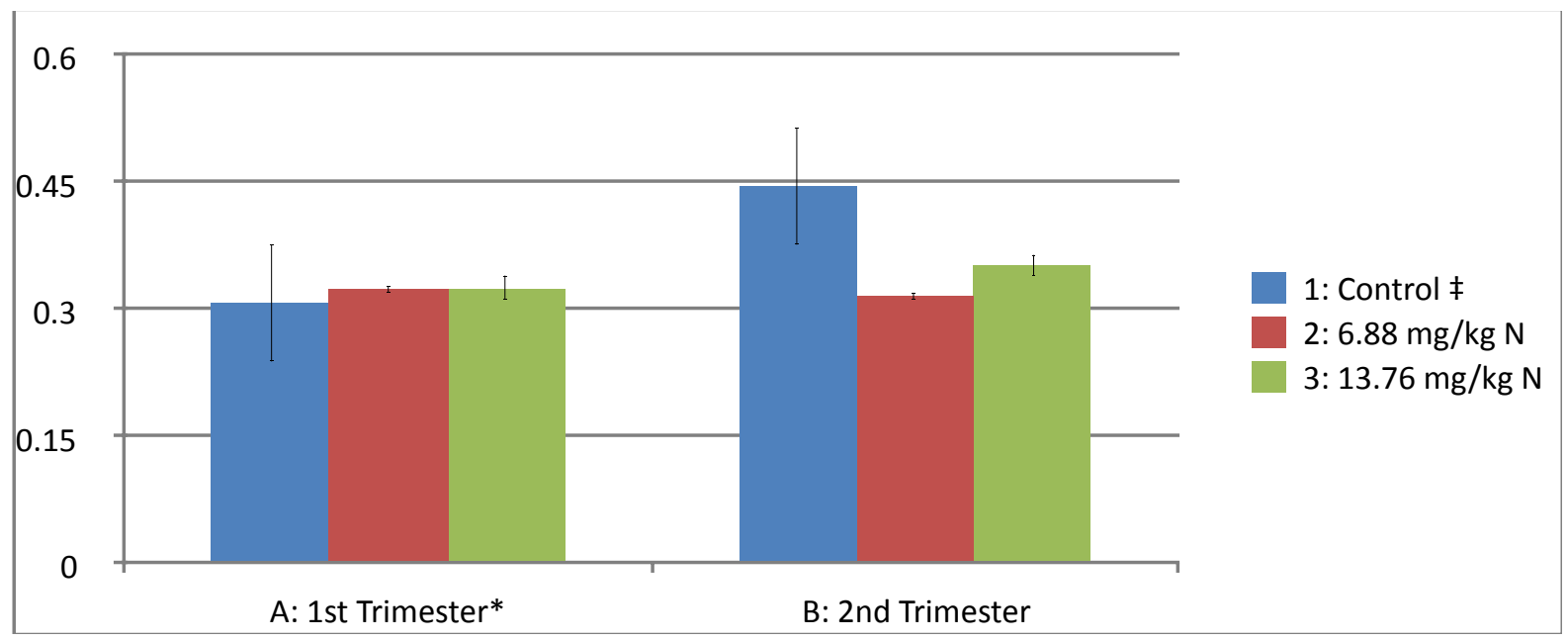

Figure 1: Brain weights of the experimental rats (significant difference in *the high dose group $\mathrm{C}$ compared with the Control in the $1^{\text {st }}$ Trimester; and, "

There was a progressive reduction $(p>0.05)$ in the weights of the frontal cortex in all groups, with the exception of the high dose group of the $1^{\text {st }}$ week, where the frontal cortical weight was higher than the control $(p$ $>0.05$ ) (Figure 2).

\section{Quantitative Biochemical Analysis}

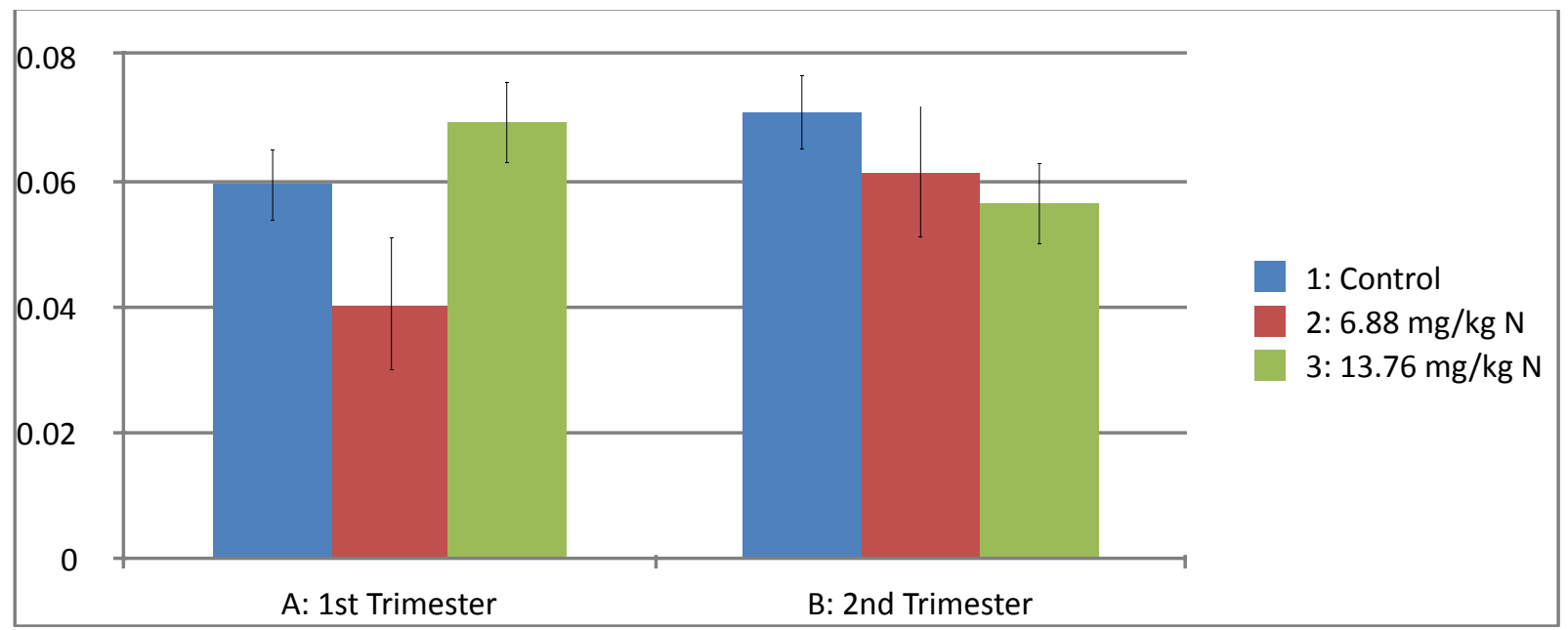

Figure 2: Weights of the frontal cortex

Table 2: Activity of alkaline phosphatase in the $1^{\text {st }}$ and $2^{\text {nd }}$ weeks of gestation (in IU/L)

\begin{tabular}{|llll|} 
& Control & $\begin{array}{l}\text { Low dose } \\
\text { nicotine }\end{array}$ & $\begin{array}{l}\text { High dose } \\
\text { nicotine }\end{array}$ \\
\hline A: $1^{\text {st }} \mathrm{GW}$ & $37.33 \pm 1.3^{\ddagger}$ & $60.50 \pm 1.5^{*}$ & $42.00 \pm 1.0^{*}$ \\
B: $2^{\text {nd }} \mathrm{GW}$ & $48.00 \pm 1.2^{\ddagger}$ & $56.00 \pm 1.0$ & $66.00 \pm 1.0$ \\
\hline
\end{tabular}


*Significant difference in ALP activity between the low dose group $B$ and the high dose group $C$ in the $1^{\text {st }}$ Trimester $(p<0.05)$, and "between the control groups of both trimesters $(p<0.05)$. GW: gestational week

Table 3: Activity of malondialdehyde in the $1^{\text {st }}$ and $2^{\text {nd }}$ weeks of gestation (in $\mu \mathrm{mol} / \mathrm{L}$ )

\begin{tabular}{|llll|} 
& Control & $\begin{array}{l}\text { Low dose } \\
\text { nicotine }\end{array}$ & $\begin{array}{l}\text { High dose } \\
\text { nicotine }\end{array}$ \\
\hline A: $1^{\text {st }} \mathrm{GW}$ & $46.00 \pm 1.2^{\ddagger}$ & $38.00 \pm 1.0^{*}$ & $44.50 \pm 1.5^{*}$ \\
B: $2^{\text {nd }} \mathrm{GW}$ & $27.67 \pm 1.2^{\ddagger *}$ & $40.00 \pm 1.0$ & $21.00 \pm 1.0^{*}$ \\
\hline
\end{tabular}

*Significant difference in MDA activity between the low dose group $B$ and the high dose group $C$ in the $1^{\text {st }}$ Trimester; between the high dose group $C$ and the control group in the $2^{\text {nd }}$ Trimester $(p$ $<0.05)$, and "between the control groups of both trimesters ( $p<0.05)$. GW: gestational week

The activity of MDA decreased in the $1^{\text {st }}$ week, with a much lower activity seen in the low dose group compared to the high dose group ( $p$ $<0.05$ ) (Table 3). Nicotine exposure during the $2^{\text {nd }}$ week caused a significantly reduced MDA activity $(p<0.05)$ in the high dose group, while in the low dose group, a marked increase activity $(p>0.05)$ was noticed compared to the control.

No statistically significant difference in the weights, ALP and MDA levels between the low dose groups of the 2 weeks, and the high dose groups of the 2 weeks. However, significant statistical difference exists between the control groups of both weeks, except in the weights of the frontal cortex.

\section{Histological Observation}

The histology of the frontal cortex of rats exposed to nicotine in the $1^{\text {st }}$ week showed less distinct outer granular and pyramidal layers (Figure 3B, C). The general architecture was distorted, compared to the control that showed distinct cortical layers with dense population of cells (small pyramidal and stellate cells) in the outer granular layer (Figure 3A). Frontal cortical layers in animals exposed during the $2^{\text {nd }}$ week were poorly defined (Figure 4B), population of neurons and cortical thickness of the outer granular layer were reduced in the high dose group, with evidence of cellular degeneration, such as vacuolations and presence of hypochromic cells (Figure 4C).
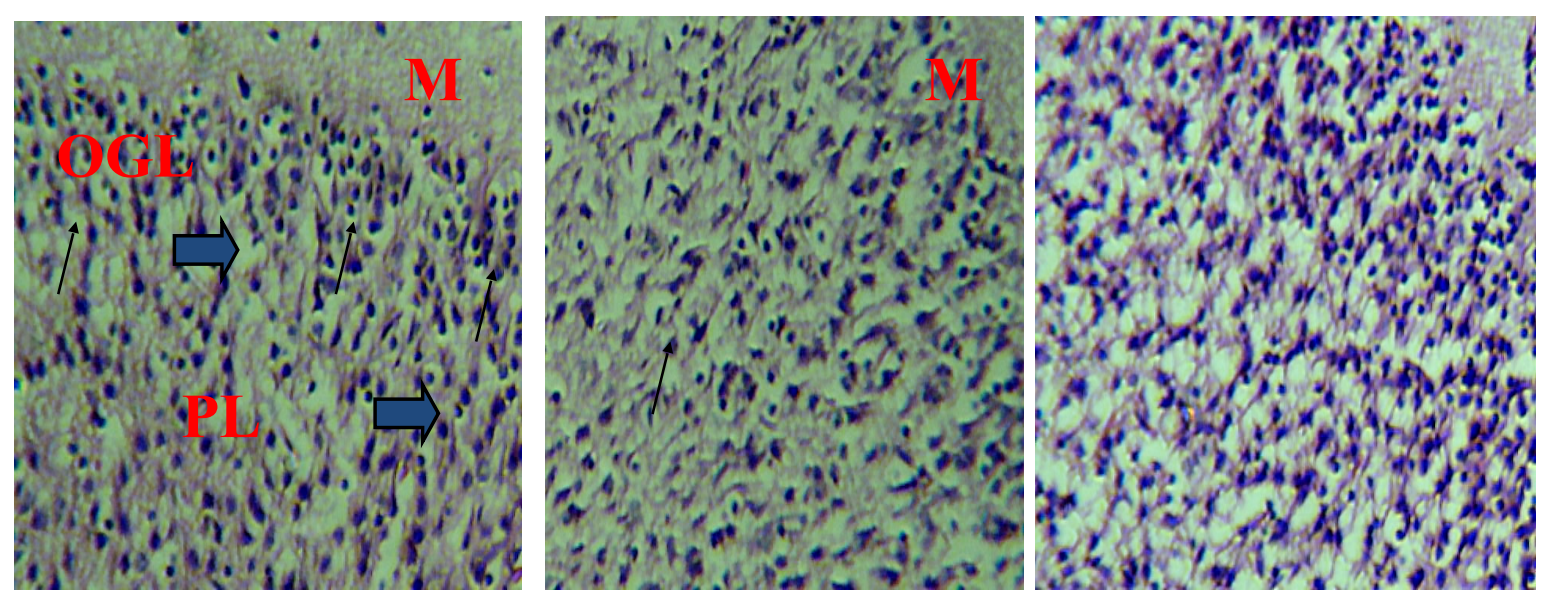

Figure 3: Photomicrographs of frontal cortex of rats in the $1^{\text {st }}$ Week group: Control (A) showing the molecular layer (M), outer granular layer (OGL) with dense population of neurons mostly small pyramidal (small arrows) and stellate cells (thick arrows). The pyramidal cell layer (PL) contains moderate size of pyramidal neurons; Figures B (low dose group) and C (high dose group) showed leş distinct OGL and PL, slightly 

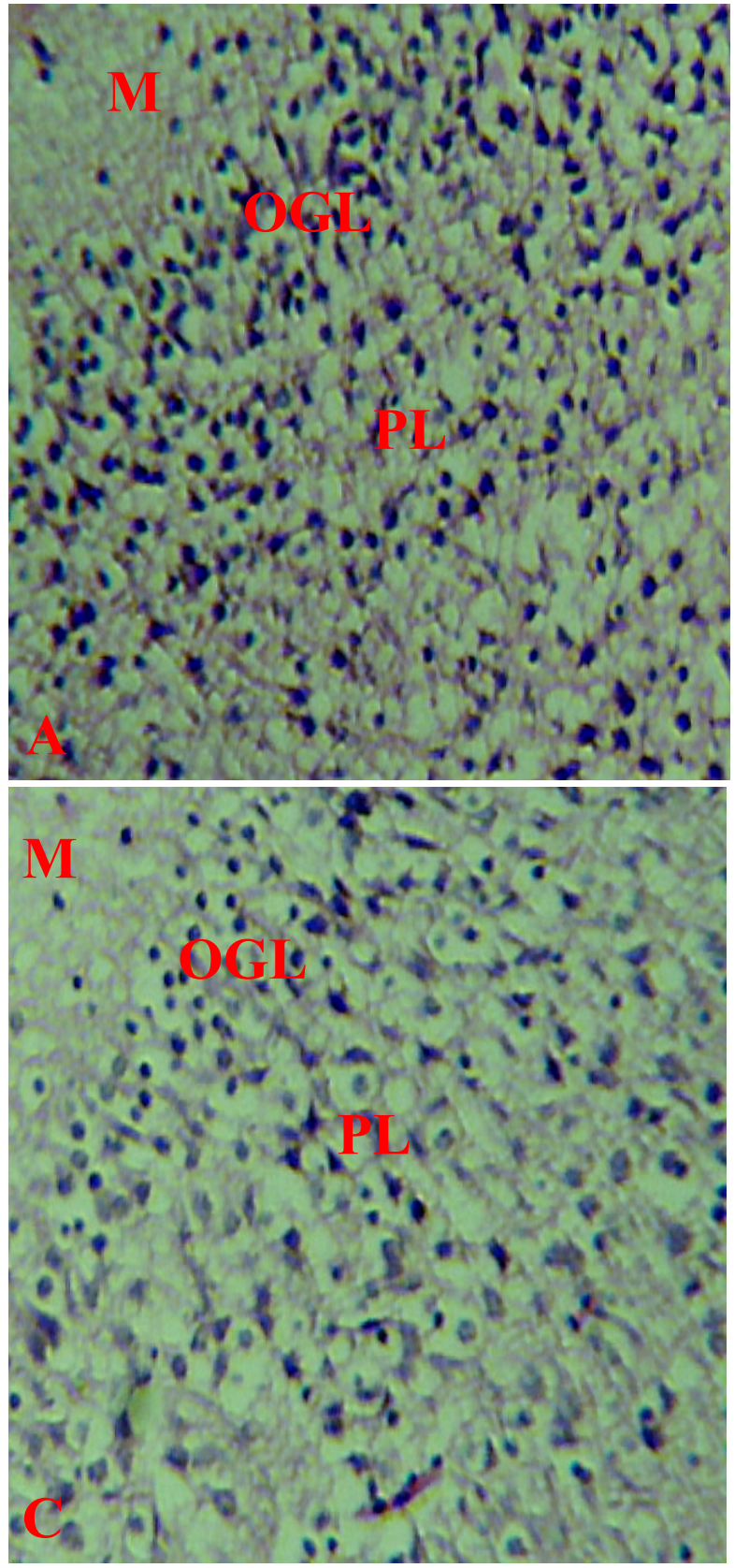

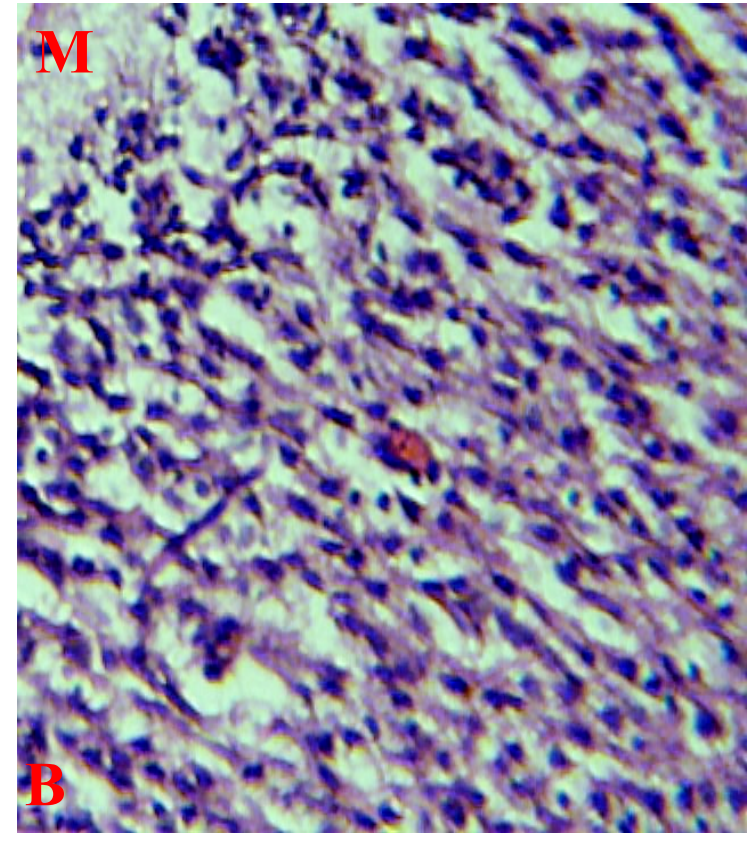

Figure 4: Photomicrographs of frontal cortex of rats in the $2^{\text {nd }}$ Week group: Control (A) shows the 3 superficial cortical layers molecular layer (M), outer granular layer (OGL) and the pyramidal cell layer (PL). Figure B (low dose group) was distorted with poorly defined cortical layers and increased staining intensity. Figure $\mathrm{C}$ (high dose group) showed less distinct OGL and PL, reduced thickness of OGL and reduced population of pyramidal and stellate cells, hypochromic cells, and vacuolar spaces. H\&E x100.

\section{DISCUSSION}

The use of nicotine or cigarette smoking during pregnancy has been linked by different authors to the occurrence of low birth weight in the newborn (Iranloye and Bolarinwa, 2009; Omotoso et al., 2014). The current study observed similar findings in a dose-dependent pattern. Irrespective of the time of prenatal nicotine exposure, the higher the dosage of the drug the lower the birth weight of the newborn; and, this was very significant. This study also showed that exposure to a low dose of nicotine during the $2^{\text {nd }}$ week of gestation rarely result in significant low birth weight, except if the amount of the drug administered is on the high side. On the contrary however, exposure of the foetus to only a small quantity of nicotine in the $1^{\text {st }}$ week is sufficient to induce a very marked decrease in birth weight. Changes in weights of animals at PND 4 did not correlate significantly with the weights of the brain and frontal cortex. In the $1^{\text {st }}$ week, an increase in these parameters was noticed in most of the groups, while in the $2^{\text {nd }}$ week category, all the groups had a decrease in the weights of the brain and frontal cortex.

Irrespective of the time of exposure, prenatal nicotine caused an increase in activity of ALP in the frontal cortex. Alkaline phosphatase, which 
is usually found in association with microsomal and cell membranes, is involved in membrane transport, and hence could result in increased mobility of substances in and out of the cell, leading to a disequilibrium state that could affect cellular composition and functions. The presence of increased ALP activity also reflected in the microarchitecture of the frontal cortex with evidence suggestive of distortions, degenerative changes and possible on-going cell death. These changes were particularly obvious in animals exposed to prenatal nicotine during their $2^{\text {nd }}$ week of gestation.

Studies on the liver indicated that prenatal nicotine exposure did not affect MDA levels at birth, but led to a significant reduction in MDA levels when examined after the first ten days (PND 10) of life (Sheng et al., 2001). The current study on the frontal cortex, similarly, observed significant low levels of MDA in rats exposed to nicotine during the $1^{\text {st }}$ and $2^{\text {nd }}$ gestational weeks, particularly when the dose of the drug was high. Malondialdehyde is used as a marker to assess lipid peroxidation especially when its levels are raised (Buege and Aust, 1978). In this study, the low levels of MDA did not suggest any lipid peroxidation at postnatal day 4. However, animals exposed to a low dose of nicotine during the $2^{\text {nd }}$ gestational week had an increase in MDA levels; this was not significant when subjected to statistical analysis.

In conclusion the foetus is more susceptible to the low birth weight effect of nicotine if exposed during the $1^{\text {st }}$ gestational week to a small concentration, and if exposed to a high dose during the $2^{\text {nd }}$ week. Changes in the activity of ALP and MDA correlate with histological findings that showed evidence of degenerative changes in the cytoarchitecture of the frontal cortical layers. These abnormalities are possible factors underlying the neurological and neurobehavioural problems demonstrated by offspring of women smokers during their childhood period.

\section{REFERENCES}

1. Blood-Siegfried J, Rende EK. 2010. The Long-Term Effects of Perinatal Nicotine Exposure on Neurologic Development. J Midwifery Womens Health 55(2): 143-152. Rogers JM. 2008. Tobacco and pregnancy: overview of exposures and effects. Birth Defects Res $C$ Embryo Today 84(1):1-15.

2. Buege JA, Aust SD. Microsomal Lipid Peroxidation. In: Fleischer, S., Packer L., (Editors) 1978. Methods in Enzymology. New York, Academic Press. p 302-330.

3. Castles A, Adams EK, Melvin CL, Kelsch C, Boulton ML. 1999. Effects of smoking during pregnancy. Five meta-analyses. Am J Prev Med. 16(3):208-15.

4. Durazzo TC, Gazdzinski S, Meyerhoff DJ. 2007. The neurobiological and neurocognitive consequences of chronic cigarette smoking in alcohol use disorders. Alcohol and Alcoholism 42(3):174-185.

5. Ejaz S, Seok KB, Woong LC. 2005. Toxicological effects of mainstream whole smoke solutions on embryonic movements of the developing embryo. Drug and Chemical Toxicology 28(1):1-14.

6. Ferrari R, Le Novère N, Picciotto MR, Changeux JP, Zoli M. 2002. Acute and long-term changes in the mesolimbic dopamine pathway after systemic or local single nicotine injections. Eur J Neurosci. 15(11):1810-8.

7. Iranloye BO, Bolarinwa AF. 2009. Effect of nicotine administration on weight and histology of some vital visceral organs in female albino rats. Nigerian Journal of Physiological Sciences 24(1):7-12.

8. Key APF, Ferguson M, Molfese DL, Peach K, Lehman C, Molfese VJ. 2007. Smoking during Pregnancy Affects Speech-Processing Ability in Newborn Infants. Environ Health Perspect. 115(4): 623-629.

9. Kohlmeier KA. 2015. Nicotine during pregnancy: changes induced in neurotransmission, which could heighten proclivity to addict and induce maladaptive control of attention. Journal of Developmental Origins of Health and Disease 6(3)169-181.

10.Lavezzi AM, Ottaviani G, Matturri L. 2007. Ontogenesis of human cerebellar cortex and biopathological characterization in sudden unexplained fetal and infant death. Virchows Archiv 450(1):31-40. 
11.Linnet KM, Dalsgaard S, Obel C, Wisborg K, Henriksen TB, Rodriguez A, et al. 2003. Maternal lifestyle factors in pregnancy risk of attention deficit hyperactivity disorder and associated behaviours: review of the current evidence. Am J Psychiatry 160(6):1028-40.

12. Marcondes FK, Bianchi FJ, Tanno AP. 2002. Determination of Oestrous Cycle Phase of Rats: Some Helpful Considerations. Braz J Biol 62(4a):609-614.

13. Murray RK, Granner DK, Mayes PA, Rodwell VW. 2003. Harper's Illustrated Biochemistry. 26th ed. New York, McGraw-Hill. p 109.

14.Omotoso GO, Ibitolu JO, Femi-Akinlosotu OM, Akinola OB, Enaibe BU. 2013. Morphological and neurohistological changes in adolescent rats administered with nicotine during intrauterine life. Nigerian Journal of Physiological Sciences 28(2):147-151.

15.Omotoso, G.O., Adekeye, M.O., Ariyo, A.A., Ibitolu, J.O., Oyeyemi, O.A., Enaibe, B.U. 2014. Neurohistochemical studies of adolescent rats' prefrontal cortex exposed to prenatal nicotine. Ibnosina Journal of Medicine and Biomedical Sciences 6(1):25-30.

16. Omotoso, GO., Adeyemi, HA. 2014. Effect of prenatal cigarette smoke exposure on the architecture of the heart in juvenile Wistar rats. Anatomy Journal of Africa 3(3):405-411.

17.Oyewopo, A.O., Saalu, L.C., Osinubi, A.A., Imosemi, I.O., Omotoso, G.O., Adefolaju, G.A. 2010. The attenuating effect of Zinc on Propoxur-induced oxidative stress, impaired spermatogenesis and deranged steroidogenesis in Wistar rats. Journal of Medicine and Medical Sciences, 1(5):178-184.

18. Roy TS, Seldler FJ, Slotkin TA. 2002. Prenatal nicotine exposure evokes alterations of cell structure in hippocampus and somatosensory cortex. Pharmacology \& Experimental Therapeutics 300(1):124-133.

19.Sheng HP, Yuen ST, So HL, Cho $\mathrm{CH}$. 2001. Hepatotoxicity of prenatal and postnatal exposure to nicotine in rat pups. Exp Biol Med (Maywood). 226(10):934-9.

20.Slotkin TA, Pinkerton KE, Auman JT, Qiao D, Seidler FJ. 2002. Perinatal exposure to environmental tobacco smoke upregulates nicotinic cholinergic receptors in monkey brain. Developmental Brain Research 133(2):175-179.

21.Yildiz D, Ercal N, Armstrong DW. 1998. Nicotine enantiomers and oxidative stress. Toxicology 130:155-165. 